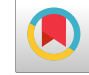

\title{
Predictors of a Health-Promoting Lifestyle in Women of Reproductive
}

\section{Age}

\author{
Masoumeh Bayat ${ }^{1}$, Mansour Sharifi ${ }^{2,}{ }^{*}$, Ali Pezhhan ${ }^{3}$, Ali Baghaei Sarabi ${ }^{4}$ and Fariba Shayegan ${ }^{5}$ \\ ${ }^{1}$ Ph.D. Student in Demography, Islamic Azad University, Science and Research Branch, Tehran, Iran \\ ${ }^{2}$ Assistant Professor in Demography, Islamic Azad University, Garmsar Branch, Garmsar, Iran \\ ${ }^{3}$ Assistant Professor in Demography, Islamic Azad University, Tehran Central Branch, Tehran, Iran \\ ${ }^{4}$ Assistant Professor in Sociology, Islamic Azad University, Roodehen Branch, Roodehen, Iran \\ ${ }^{5}$ Professor, Amin Police University, Tehran, Iran \\ "Corresponding author: Assistant Professor in Demography, Islamic Azad University, Garmsar Branch, Garmsar, Iran. Email: sharifim@ut.ac.ir
}

Received 2020 October 12; Accepted 2020 October 12.

\begin{abstract}
Background: Considering that women are the main components of family health and the main models for education and promotion of healthy lifestyles to the next generation, the study of lifestyle and effective factors in promoting women's health, especially at reproductive age, is of great importance.

Objectives: The present study aimed to determine the predictors of a health-promoting lifestyle in women of reproductive age in Zahedan based on Pender's health promotion model (HPM).

Methods: This descriptive cross-sectional study was conducted on a sample of 200 women aged 15 - 49 in Zahedan, Southeastern Iran, using multi-stage cluster sampling in 2019. The instruments used to collect the data were the demographic information form, the Perceived Self-Efficacy scale, the Perceived Social Support scale, the Perceived Emotions scale, the Perceived Barriers scale, and the health-promoting lifestyle profile II. The collected data were analyzed by descriptive statistics, Pearson correlation coefficient, independent samples $t$-test, one-way analysis of variance (ANOVA), and multiple linear regression analysis using the enter method in SPSS software (version 25).

Results: The mean score of health-promoting lifestyle was $69.82 \pm 13.59$ out of the score range of 32 to 128 . The highest and lowest mean scores were related to the nutrition subscale $(20.08 \pm 4.3)$ and the exercise subscale $(14.19 \pm 4.51)$, respectively. It was shown that the health-promoting lifestyle had a significant positive correlation with perceived self-efficacy, perceived social support, and perceived emotions $(\mathrm{P}=0.001)$ and a significant negative correlation with perceived barriers $(\mathrm{P}=0.005)$. The results of multiple linear regression analysis showed perceived self-efficacy $(\mathrm{P}=0.001)$, perceived social support, and perceived emotions were predictors of a health-promoting lifestyle in women of reproductive age $(\mathrm{P}=0.05, \mathrm{P}=0.001)$, and these three variables together predicted $37 \%$ of the variations in the health-promoting lifestyle score.

Conclusions: This study showed that women with $54.68 \%$ of the total lifestyle score did not have an acceptable lifestyle. Besides, perceived self-efficacy was the most important factor and the strongest predictor of women's health-promoting lifestyle. Accordingly, some interventions must be planned and implemented to improve the health-promoting lifestyle in women of reproductive age and increase their self-efficacy.
\end{abstract}

Keywords: Pender's Health Promotion Model, Lifestyle, Women of Reproductive Age

\section{Background}

Currently, lifestyle modification, especially attention to health-promoting lifestyle, is a prerequisite for maintaining and promoting individuals' health (1). Many health problems, various chronic diseases such as obesity, various cancers, hypertension, diabetes, and the deaths caused by them are the result of people's unhealthy behavior and lifestyle (2). If behavioral and lifestyle problems are identified and changed in time, their adverse consequences on health will be prevented (3).
In its declaration at the First World Conference on Healthy Living in Moscow, the World Health Organization (WHO) stated that $60 \%$ of the deaths worldwide and $80 \%$ of deaths in developing countries are due to unhealthy lifestyles, increasing to $75 \%$ of the deaths worldwide by 2030 (4). Thus, modern health care has gradually shifted its focus from examining mortality as a health consequence to broader areas such as health promotion, lifestyle, and quality of life (5).

A health-promoting lifestyle empowers people to in- 
crease control over and improve their health (6). A healthpromoting lifestyle is known as a balanced lifestyle in which people always make informed choices about their health and well-being and improve their health by engaging in behaviors such as regular physical activity and a healthy diet, establishing friendly relationships with others, controlling and reducing stress in daily life, and other health-promoting activities (7).

One of the widely-used models for predicting factors affecting health-promoting behaviors and quality of life is Pender's health promotion model that includes the concepts that determine health-promoting behaviors such as personal experiences and characteristics, specific feelings, cognitive-perceptual elements, and behavioral outcomes. Individual characteristics and experiences have direct or indirect effects on the likelihood of engaging in health-promoting behaviors through cognition and emotions and include personal factors and similar behaviors in the past. Cognition and specific emotions directly affect behavior and include constructs such as perceived benefits and barriers, perceived self-efficacy, behavior-related emotions, interpersonal influencers, and situational influencers. According to Pender, health-promoting behaviors, especially when adapted to a healthy lifestyle, lead to the development of health, the improvement of structural abilities, and a better quality of life at all stages of development (8).

The four most important components of a healthpromoting lifestyle include nutrition, exercise, stress management, and health responsibility. A review of previous studies suggests that lifestyle correlates with individual-societal characteristics $(9,10)$. Some studies have shown that people with lower levels of education are less likely to follow health-promoting behaviors (11, 12). Living with a partner increases the likelihood of following health-promoting behaviors (11), and the healthpromoting lifestyle is related to economic status and social class (13) and the number of family members (14). Previous studies (e.g., Hajizadeh Meimandi and Dehghan Chenary, 2015; Hirth, 2010; Rakhshani et al., 2014) have indicated that married people have a better health-promoting lifestyle. A study by Mirghafourvand et al. (15) in Tehran on women of childbearing age also showed that social support, age, marriage, and education are related to healthpromoting behaviors. Movahed et al. (16) showed that social support is the most important factor in the lifestyle of the elderly and is a strong determinant promoting the health of individuals. Zanjeri (17) highlighted the importance of self-efficacy in women's lifestyle and considered it the most important factor after social support. A study by Mirghafourvand et al. (15) showed that age and income are the factors associated with health-promoting behaviors.
Experts also believe that a health-promoting lifestyle is a useful source to reduce life stressors and has a significant effect on reducing health costs, increasing people's life expectancy, and improving their quality of life. Therefore, such a lifestyle has special importance and position in society (18). Besides, paying attention to the health and social welfare of women, who make up half of the population, is not only recognized as a right, but it has received considerable attention due to its impact on family and community health. In addition, since women play a vital role in caring for themselves, children, the elderly, the sick, and other family members at home (19), women's choice of lifestyle not only affects their personal life but also other people's lifestyles and behaviors. Accordingly, disregard for women's health can lead to permanent problems related to the lifestyle and health of future generations (20).

According to the latest 2016 Population and Housing Census, the population of Sistan and Baluchestan Province is 2775014 persons, and the population of women of childbearing age is 720459 people, accounting for $52 \%$ of the population of women and $26 \%$ of the population of the province. However, there is little research on the healthpromoting lifestyle of women of reproductive age. The total fertility rate in the province is 3.96 , which is the highest fertility rate in the country (21). Furthermore, sociocultural conditions, underdevelopment, low literacy, the lack of full access to health care facilities, and social inequalities always threaten the health of women in this province, so that they have lower ranks in most health indicators compared to the national average.

\section{Objectives}

Considering that health promotion activities and a healthy lifestyle are the main strategies to facilitate and protect health, and since no study has addressed the health-promoting lifestyle and its factors among women of reproductive age in the province, the present study aims to determine the predictors of a health-promoting lifestyle among women aged 15 - 49 based on Pender's health promotion model.

\section{Methods}

The present study is a descriptive-analytical crosssectional study conducted in the fall of 2019. The respondents were 200 women aged 15 - 49 living in Zahedan who were randomly selected from five districts of the city using the multi-stage sampling method. To this end, based on the latest census and blocking of the Statistical Centre of Iran, the urban districts were selected as clusters, and two 
blocks were randomly selected from each cluster. Then, of every two women meeting the inclusion criteria in each block, one woman was selected randomly. Accordingly, 20 women aged 15 - 49 years were selected from each block. The inclusion criteria were being at the age of 15 - 49, having no drug addiction, and having no history of underlying diseases and mental health problems.

The sample size was calculated using the Cochran's formula and based on the population of 15 - 49 women in Zahedan and lifestyle variance (Mohamadian et al., 2011) with 95\% confidence interval and 95\% test power (Equation 1):

$n=\frac{N Z^{2} S^{2}}{N d^{2}+Z^{2} S^{2}}=199$

Where $Z=1.96, S^{2}=0.13, d=0.05$, and $N=182483$.

The instruments used to collect the data were the demographic information form, the Perceived Self-Efficacy scale, the Perceived Social Support scale, the Perceived Emotions scale, the perceived barriers scale, and the health-promoting lifestyle profile II (HPLP II):

The Demographic Information Form: It was used to assess the respondents' age, education, occupation, household income, ethnicity, religion, and the number of children.

The Perceived Self-Efficacy Scale: The scale was adapted from the Smith et al.'s Health scale, and it contains 8 items scored based on a 5-point Likert scale ranging from "strongly agree" to "strongly disagree". The score range on this scale is from 8 to 40 , with a higher score on this scale indicating that the individual has a high ability to control the outcomes and consequences of his/her health-related programs. Smith et al. (22) estimated the reliability of the scale equal to 0.84 using Cronbach's alpha coefficient. In the present study, the reliability of the scale was calculated as 0.77 using Cronbach's alpha coefficient.

The Perceived Social Support Scale: The scale was adapted from the scale developed by Canty-Mitchell and Zimet (23) This scale measures social support received from three separate sources, including family, friends, and significant others. The scale contains 12 items ( 4 items for each source) that are scored on a seven-point Likert scale ranging from "strongly agree" to "strongly disagree". The total score for each source ranges from 4 to 24 , and a higher score indicates more support from family, friends, and significant others. The Cronbach's alpha value reported by Canty et al. for the whole scale was 0.91, and the corresponding values for each source vary from 0.90 to 0.95 (23). In the present study, the reliability of the scale was calculated and reported as 0.88 using Cronbach's alpha coefficient.

The Perceived Emotions Scale: This scale was developed based on Watson et al.'s (24) tool and contains 20 items that are scored on a 5-point Likert scale from "never" to "always". The scale has two subscales, including positive affect (10 items) and negative affect (10 items). The total score on each subscale ranges from 10 to 50 with a higher score reporting better emotional states over the past 24 hours. Watson et al. reported a Cronbach's alpha coefficient of 0.94 for positive affect and 0.91 for negative affect (24). In the present study, the reliability of the instrument was calculated using Cronbach's alpha coefficient with a value of 0.75 .

The Perceived Barriers Scale: The instrument was adapted from a scale developed by Becker and Stuifbergen (25) and contains 18 items scored on a 4-point Likert scale ranging from "never" to "always". The total score ranges from 18 to 72, and a higher score indicates that the respondent faces more barriers to engagement in healthpromoting behaviors. Cronbach's alpha coefficient was reported by Becker et al. 0.80 , and the test-retest coefficient was 0.75 (25). In the present study, the reliability of the instrument was calculated using Cronbach's alpha coefficient as 0.83 .

The Health-Promoting Lifestyle Profile II: This instrument was developed by Walker et al. (26) and contains 32 items that are scored based on a 4-point Likert scale ranging from "never" to "always" and are categorized into four subscales: nutrition, exercise, stress management, and health responsibility. The total score on this scale ranges from 32 to 128, and higher scores indicate that respondents are following a better health-promoting lifestyle. Cronbach's alpha coefficient for the tool was reported by Walker et al. as equal to 0.94 (26). The reliability of the instrument was calculated using Cronbach's alpha coefficient in the present study, and the related value was 0.89 .

Trained interviewers referred to the respondents' homes to complete the questionnaires. The questionnaires for each respondent were completed in one session. If the respondent was literate, she would complete the questionnaire after receiving some instructions from the interviewer on how to answer the questions. However, if the respondent was illiterate, she would be interviewed, and the questionnaires would be completed by the interviewer. All respondents in the present study were informed of the objectives of the study, and informed written consent was obtained from them. Besides, to ensure the confidentiality of the information, the questionnaires were completed without recording the respondents' names.

The collected data were analyzed through descriptive statistics, Pearson correlation coefficient, independent samples $t$-test, one-way analysis of variance (ANOVA), and multiple linear regression analysis using the enter method in SPSS software (version 25). Before doing mul- 
tivariate analysis, regression assumptions, including normality and homoscedasticity of residuals, the collinearity of outlier data, and residual independence, were checked. All statistical procedures were performed at a significant level of less than $0.05(\mathrm{P}<0.05)$.

\section{Results}

The mean age of the respondents was $31.36 \pm 8.53$ years. Most respondents were married (74\%). Besides, 30.5\% of them were employed, and $34.5 \%$ had associate's and bachelor's degrees. Furthermore, 54.5\% of the respondents stated that their access to health services was moderate.

The mean score of health-promoting lifestyle for the respondents was $69.82 \pm 13.59$. Besides, among the lifestyle subscales, nutrition and exercise had the highest and lowest mean scores ( $20.08 \pm 4.23$ vs. $14.19 \pm 4.51)$, respectively (Table 1).

Table 1. The Descriptive Statistics for the Health-Promoting Lifestyle and Its Subscales $^{\mathrm{a}}$

\begin{tabular}{lcc}
\hline Variable & Values & Range \\
\hline $\begin{array}{l}\text { The total score of the health-promoting } \\
\text { lifestyle }\end{array}$ & $69.82 \pm 13.59$ & $32-128$ \\
Nutrition & $20.08 \pm 4.23$ & $8-32$ \\
\hline Exercise & $14.19 \pm 4.51$ & $8-32$ \\
Stress management & $19.02 \pm 4.27$ & $8-32$ \\
\hline Health responsibility & $16.25 \pm 4.61$ & $8-32$ \\
\hline
\end{tabular}

${ }^{\mathrm{a}}$ Values are expressed as mean $\pm \mathrm{SD}$.

The results of one-way ANOVA and independent samples $t$-test indicated that the respondents' mean scores of health-promoting lifestyle were not significantly different in terms of age, education, household income, and the number of children. However, the respondents' lifestyle showed significant differences in terms of marital status and access to health services $(P=0.02)$. For instance, the married respondents (with a mean score of 71.33) and those who had high and very high access to health services (with a mean score of 72.72) had a healthier lifestyle than other groups (Table 2).

The results of the study concerning the relationship between health-promoting lifestyle and the variables in Pender's health-promoting model suggested that healthpromoting lifestyle had a significant positive relationship with perceived self-efficacy, perceived social support, and perceived emotions $(\mathrm{P}<0.001)$, and a negative relationship with perceived barriers $(P=0.005)$. Perceived selfefficacy also had the highest correlation with the women's health-promoting lifestyle $(r=0.56)$ (Table 3 ).

\begin{tabular}{|c|c|c|c|c|}
\hline Variable & Number & Values & $\mathbf{F}$ & PValue $^{\text {b }}$ \\
\hline Marital status & & & 3.97 & 0.02 \\
\hline Single & 46 & $66.08 \pm 12.58$ & & \\
\hline Married & 148 & $71.33 \pm 13.57$ & & \\
\hline Divorced/widow & 6 & $61.16 \pm 12.79$ & & \\
\hline $\begin{array}{l}\text { Access to healthcare } \\
\text { services }\end{array}$ & & & 3.72 & 0.02 \\
\hline Low & 19 & $64 \pm 12.97$ & & \\
\hline Moderate & 109 & $68.91 \pm 14.18$ & & \\
\hline High & 72 & $72.72 \pm 12.26$ & & \\
\hline
\end{tabular}

${ }^{\mathrm{a}}$ Values are expressed as mean $\pm \mathrm{SD}$.

${ }^{\mathrm{b}}$ One-way ANOVA

Table 3. The Correlations between Health-Promoting Lifestyle and the Variables in the Health Promotion Model

\begin{tabular}{lcc}
\hline Variable & Correlation $(\mathbf{r})$ & P Value \\
\hline Perceived self-efficacy & 0.56 & 0.001 \\
Perceived social support & 0.48 & 0.001 \\
Perceived emotions & 0.16 & 0.01 \\
Perceived barriers & -0.19 & 0.005 \\
\hline
\end{tabular}

Multiple linear regression analysis was run to evaluate the predictors of a health-promoting lifestyle. The results showed that perceived self-efficacy was the strongest predictor of a health-promoting lifestyle $(\mathrm{P}<0.001)$. In total, the three variables of perceived self-efficacy, perceived social support, and perceived emotions were able to predict $37 \%$ of lifestyle variations, and perceived barriers had no role in predicting lifestyle (Table 4 ).

\section{Discussion}

The present study showed that the health-promoting lifestyle had a significant positive relationship with perceived self-efficacy, perceived social support, and perceived emotions and negatively correlated with perceived barriers. In other words, as perceived self-efficacy, perceived social support, and perceived emotions increase, people are encouraged to follow a health-promoting lifestyle. However, as perceived barriers increase, people are less likely to follow a health-promoting lifestyle.

It was also shown that of variables in the health promotion model, perceived self-efficacy, which refers to the evaluation and judgment of an individual about his/her ability to maintain or improve health is the most important factor for predicting health-promoting lifestyle among the women. This finding is in line with those of the studies that 


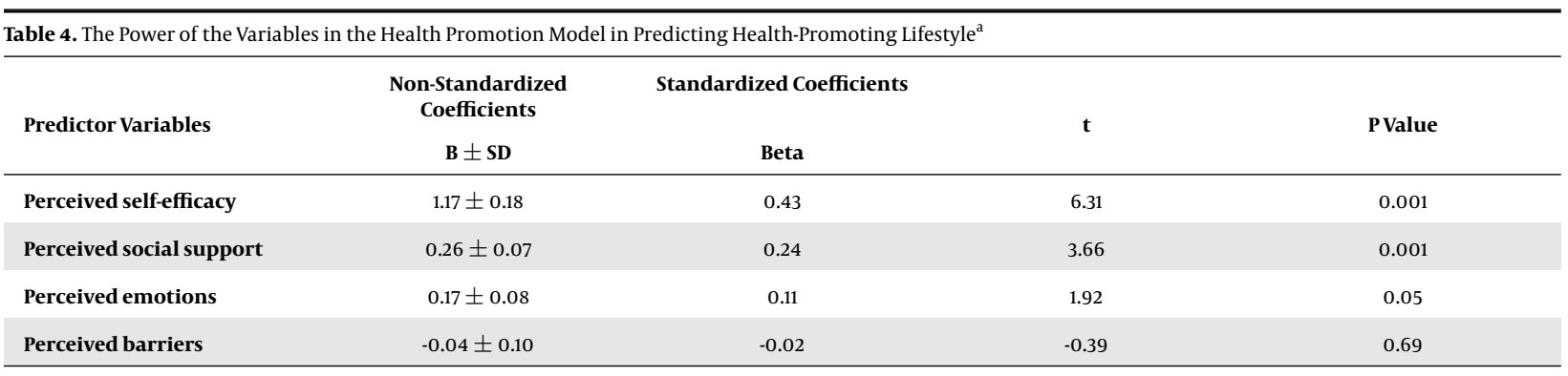

${ }^{\mathrm{a}} \mathrm{R}=0.62 ; \mathrm{R}^{2}=0.38 ;$ adjusted $\mathrm{R}^{2}=0.37 ;$ constant $=0.434 ;$ Durbin Watson $=1.92 ; \mathrm{F}=30.42 ; \mathrm{P}<0.001$.

applied Pender's health promotion model (27-29). Most studies that applied the health promotion model highlighted self-efficacy as the most effective factor in performing health-promoting behaviors $(29,30)$.

The results of the present study concerning the subscales of the health-promoting lifestyle showed that the women of the reproductive age had the highest score on nutrition and the lowest score on exercise, implying that they followed a satisfactory lifestyle in terms of nutrition but an undesirable lifestyle in terms of exercise. Similarly, Yarahmadi and Rousta (31) reported the highest score for nutrition and the lowest score for physical activity. Furthermore, Hosseinnejad and Klantarzadeh reported that students had a moderate score for nutrition but had a lower score for physical activity (32), as was observed in the present study. In contrast, Dukas et al. (33) showed that Spanish pregnant women followed a moderate nutritional style and an optimal physical activity style. Another study by Chen et al. (34) in Taiwan showed that pregnant women had a poor nutritional style and moderate physical activity, which is contrary to the observation made in the present study. It seems that these conflicting results are due to different cultural norms and lifestyles pursued by women in different countries.

The mean score of the women's health-promoting lifestyle in the present study was lower than average, while the health-promoting lifestyle is an important determining factor in health (30). Yarahmadi and Rousta (31) reported the mean score of the health-promoting life scale as equal to $54 \pm 12.80$ (on a scale of zero to 100) that was at a medium to a high level. Besides, Lim et al. (11) reported that the score of the health-promoting lifestyle of the studied women was close to the mean score.

The present study showed that married women followed a significantly healthier lifestyle than single people, widows, and divorced people and scored higher on average. This finding is in line with Lim et al.'s study (11). Similarly, Ghaffari Nejad and Pouya (35) found that the highest score of health-promoting behaviors was gained by married people. Marriage seems to reinforce women's sense of responsibility for choosing and following a healthier lifestyle.

The present study showed no significant relationship between age and lifestyle, as evidenced in some studies $(35,36)$. However, Singh et al. (37) and Al-kandari et al. (38) found a negative correlation between age and lifestyle, which can be due to differences in the samples under study.

Access to health services enables care, treatment, and prevention of diseases and is effective in improving a health-oriented lifestyle. Likewise, the present study showed the mean score of health-promoting lifestyle was higher in people who had high and very high access to health services than other groups. The type of study and individual, cultural, and social differences were the limitations of the study that could affect the quality of the participants' responses.

\subsection{Conclusions}

The findings of the present study showed that the women's lifestyle, physical activity, and health responsibility are not at favorable levels, and perceived self-efficacy, perceived social support, and perceived emotions were predictors of health-promoting lifestyle in the women of reproductive age and these three variables together predicted $37 \%$ of the variations in the health-promoting lifestyle score. Therefore, it is recommended that the necessary interventions and programs incorporating adequate training and information about health responsibility and regular physical activity be planned and implemented for women of reproductive age to improve the health-promoting lifestyle. Besides, given the lack of recreational and sports spaces for women in Sistan and Baluchestan Province and the importance of sports for a healthy lifestyle, related authorities must take effective measures to provide the required facilities. Given that the findings of this study highlighted the importance of self-efficacy in health-promoting lifestyles for women, health managers, and policymakers are required to design and implement effective training programs to increase women's self-efficacy. Furthermore, considering that the 
findings of this study showed that social support is the second predictor of women's lifestyle, and given the importance of interpersonal communication and social support in creating social capital and, consequently, improving women's health, it is necessary to take effective measures to strengthen women's support networks in the family and community.

\section{Acknowledgments}

This article was extracted from a doctoral dissertation in Demography at the Islamic Azad University, Tehran Science, and Research Branch. The authors would like to appreciate the honorable Vice-chancellor for Research and Technology, the officials of the Department of Demography of the Islamic Azad University, Tehran Science and Research Branch, the interviewers, and all women who contributed to conducting this study.

\section{Footnotes}

Authors' Contribution: Masoumeh Bayat, Mansour Sharifi, and Ali Pezhhan equally contributed to data collection, manuscript composition, study design, and data analysis.

Conflict of Interests: The authors declared no conflict of interest.

Funding/Support: No financial support was received for this research.

\section{References}

1. Pender NJ, Murdaugh CL, Parsons MA. Health promotion in nursing practice. Pearson; 2006

2. Chinekesh A, Hoseini SA, Shahbolaghi FM, Motlagh ME, Eftekhari MB, Ardalan G, et al. A comprehensive health plan: The lifestyle affecting factors in Iranian youth. Int J Prev Med. 2018;9:1. doi: 10.4103/ijpvm.IJPVM_309_17. [PubMed: 29416837]. [PubMed Central: PMC5787877].

3. Mansour SM, Bagheri F. [Predicting Health-promoting lifestyle from health locus of control and attachment style]. Health Psychology. 2017;4(2):131-44. Persian.

4. Declaration M. First global ministerial conference on healthy lifestyles and noncommunicable disease control. Moscow, Russia. World Health Organization; 2011.

5. Tol A, Tavassoli E, Shariferad GR, Shojaeezadeh D. Health-promoting lifestyle and quality of life among undergraduate students at school of health, Isfahan university of medical sciences. J Educ Health Promot. 2013;2:11. doi:10.4103/2277-9531.108006.[PubMed: 24083261]. [PubMed Central: PMC3778574]

6. Chen MY, Lai LJ, Chen HC, Gaete J. Development and validation of the short-form Adolescent Health Promotion Scale. BMC Public Health. 2014;14:1106. doi: 10.1186/1471-2458-14-1106. [PubMed: 25344693]. [PubMed Central: PMC4216378].

7. Chiou AF, Hsu SP, Hung HF. Predictors of health-promoting behaviors in Taiwanese patients with coronary artery disease. Appl Nurs Res. 2016;30:1-6. doi: 10.1016/j.apnr.2015.08.008. [PubMed: 27091244]
8. Pender NJ. Health promotion in nursing practice. 7th ed. Prentic Hall Publication; 2011. p. 57-64.

9. Rastegar M, Zendehtalab H, Yavari M, Mazlom S. Health-promoting lifestyle and its related factors among health volunteers Mashhad in 2015. J Torbat Heydariyeh Univ Med Sci. 2015;3(3):55-48.

10. Hasanpour L, Zohari AS, Safari M, Naderiravesh N, Khodakarim S. Fac tors associated with nurses'lifestyles in nurses of Tehran hospitals in 2012. Adv Nurs Midwifery. 2016;25(91):65-73.

11. Lim YM, Sung MH, Joo KS. Factors affecting health-promoting behaviors of community-dwelling Korean older women. J Gerontol Nurs. 2010;36(10):42-50. doi: 10.3928/00989134-20100504-05. [PubMed: 20506936]

12. Izadirad $\mathrm{H}$, Zareban I. The relationship of health literacy with health status, preventive behaviors and health services utilization in Baluchistan, Iran. J Edu Commun Health. 2015;2(3):43-50. doi: $10.20286 /$ jech-02036.

13. Zarei N. Intergenerational study of food among women in Shiraz. Shiraz, Iran: Shiraz University; 2015.

14. EftekharArdabili H,Azam K, Movahed E. Study of Mental health and its Relationship with Family Welfare in Pre-university Students in Salmas City in 2010. J Res Develop Nurs Midwifery. 2012;9(1):84-93.

15. Mirghafourvand M, Baheiraei A, Nedjat S, Mohammadi E, Charandabi SM, Majdzadeh R. A population-based study of health-promoting behaviors and their predictors in Iranian women of reproductive age. Health Promot Int. 2015;30(3):586-94. doi: 10.1093/heapro/dat086. [PubMed: 24395956].

16. Movahed M, Zanjeri N, Sadeghi R. Demographic social determinants of lifestyle promoting the health of the elderly (A case study of the elderly in Shiraz). J Population Assoc Iran. 2012;(10).

17. Zanjeri N. Lifestyle that promotes women's health in reproductive ages (Case study of Shiraz). Shiraz, Iran: Shiraz University; 2019.

18. Mo PK, Winnie W. The influence of health promoting practices on the quality of life of community adults in Hong Kong. Soc Indicat Res. 2009;95(3):503-17. doi: 10.1007/s11205-009-9523-9.

19. Ahmadi B, Farzadi F, Alimohammadian M. Women's health in Iran: issues and challenges. Payesh (Health Monitor). 2012;11(1):127-37.

20. Baheiraei A, Mirghafourvand M, Mohammadi E, Charandabi SM The experiences of women of reproductive age regarding healthpromoting behaviours: a qualitative study. BMC Public Health 2012;12:573. doi: 10.1186/1471-2458-12-573. [PubMed: 22846587]. [PubMed Central: PMC3490730].

21. Statistical Center of Iran. According to the results of the census, the total fertility rate of Iran in the period of 1391-95 reached 2.1 children. Statistical Center of Iran; 2016. Available from: https://www.amar.org.ir/news/ ID/5080.

22. Smith MS, Wallston KA, Smith CA. The development and validation of the Perceived Health Competence Scale. Health Educ Res. 1995;10(1):5164. doi: 10.1093/her/10.1.51. [PubMed:10150421].

23. Canty-Mitchell J, Zimet GD. Psychometric properties of the Multidimensional Scale of Perceived Social Support in urban adolescents. Am J Community Psychol. 2000;28(3):391-400. doi: 10.1023/A:1005109522457. [PubMed: 10945123].

24. Watson D, Clark LA, Tellegen A. Development and validation of brief measures of positive and negative affect: the PANAS scales. $J$ Pers Soc Psychol. 1988;54(6):1063-70. doi: 10.1037||0022-3514.54.6.1063. [PubMed: 3397865].

25. Becker H, Stuifbergen A. What makes it so hard? Barriers to health promotion experienced by people with multiple sclerosis and polio. Fam Community Health. 2004;27(1):75-85. doi: 10.1097/00003727 200401000-00008. [PubMed: 14724504].

26. Walker SN, Sechrist KR, Pender NJ. Health-promoting lifestyle profile II. Omaha, Nebraska, USA: University of Nebraska Medical Center, College of Nursing; 1995. Available from: https://www.unmc.edu/ nursing/faculty/health-promoting-lifestyle-profile-II.html. 
27. Roosta F, Ahmadi A. Self-efficacy and health promoting behaviors among women of reproductive ages in Shiraz during 2013. J Ilam Uni Med Sci. 2016;24(2):90-100. doi:10.18869/acadpub.sjimu.24.2.90.

28. Roozbahani N, Ghofranipour F, Eftekharardebili H, Hajizadeh E. [The relationship between self-efficacy and stage of change and physical activity behavior in postpartum women]. Arak Med Uni J. 2013:61-71. Persian.

29. Andouz Z, Dolatshahi B, Moshtagh N, Dadkhah A. The efficacy of metacognitive therapy on patients suffering from pure obsession. Iran J Psychiatry. 2012;7(1):11-21.

30. Wei CN, Harada K, Ueda K, Fukumoto K, Minamoto K, Ueda A. Assessment of health-promoting lifestyle profile in Japanese university students. Environ Health Prev Med. 2012;17(3):222-7. doi: 10.1007/s12199-0110244-8. [PubMed: 21987366]. [PubMed Central: PMC3348247].

31. Yarahmadi A, Rousta F. [Health-promoting lifestyle of women in pragnancy age].J Women Develop and policy. 2014;11(4):543-58. Persian.

32. Hosseinnejad M, Klantarzadeh M. Study of lifestyle based on the Pender's Health Promotion model among students of Islamic Azad University. Iran J Health Educ Health Promot. 2014;1(4):15-28.

33. Dukas L, Willett WC, Giovannucci EL. Association between physi- cal activity, fiber intake, and other lifestyle variables and constipation in a study of women. Am J Gastroenterol. 2003;98(8):1790-6. doi: 10.1111/j.1572-0241.2003.07591.x. [PubMed: 12907334].

34. Chen MY, James K, Wang EK. Comparison of health-promoting behavior between Taiwanese and American adolescents: a crosssectional questionnaire survey. Int J Nurs Stud. 2007;44(1):59-69. doi: 10.1016/j.ijnurstu.2005.11.015. [PubMed: 16386741].

35. Ghaffari Nejad A, Pouya F. Self promoting behaviors among teachers in Kerman. Jour Guilan Uni Med Sci. 2002;11(43):1-9.

36. Peker K, Bermek G. Predictors of health-promoting behaviors among freshman dental students at Istanbul University. J Dent Educ. 2011;75(3):413-20. [PubMed: 21368265].

37. Singh AK, Maheshwari A, Sharma N, Anand K. Lifestyle associated risk factors in adolescents. Indian J Pediatr. 2006;73(10):901-6. doi: 10.1007/BF02859283. [PubMed: 17090902].

38. Al-Kandari F, Vidal VL, Thomas D. Health-promoting lifestyle and body mass index among College of Nursing students in Kuwait: a correlational study. Nurs Health Sci. 2008;10(1):43-50. doi: 10.1111/j.14422018.2007.00370.x. [PubMed:18257831]. 